\title{
Aposentadorias e pensões no Brasil: progressivas ou regressivas?
}

\author{
Retirements and pensions in Brazil: \\ progressive or regressive?
}

RODOLFO HOFFMANN*

RESUMO: Estes comentários são uma reação ao artigo de Cardoso, Dietrich e Souza (2021) publicado no Brazilian Journal of Political Economy, vol. 41 (1), janeiro-março 2021. PALAVRAS-CHAVE: Distribuição de renda; desigualdade.

ABSTRACT: These comments are a reaction to the article by Cardoso, Dietrich and Souza (2021) published in the Brazilian Journal of Political Economy, vol. 41 (1), January-March 2021.

KEYWORDS: Income distribution; inequality.

JEL Classification: D31; D63.

Estes comentários são uma reação ao artigo de Cardoso, Dietrich e Souza (2021) publicado no Brazilian Journal of Political Economy. Na página 38 do artigo lê-se que "O Gráfico 6 mostra que, de fato, a distribuição dos rendimentos de aposentadorias e pensões reduz a desigualdade de renda". De fato, o gráfico mencionado mostra que a distribuição da renda domiciliar per capita (RDPC), no Brasil, em 2017, incluindo as aposentadorias e pensões, é menos desigual do que a distribuição da RDPC excluindo as aposentadorias e pensões. Parece óbvio, então, que as aposentadorias e pensões estão contribuindo para reduzir a desigualdade. Em Hoffmann (2009), procurei mostrar que isso é uma maneira totalmente inapropriada de avaliar se uma parcela da renda contribui para aumentar ou reduzir a desigualdade; esse trabalho é citado por Cardoso et al. como exemplo de estudos que "encontraram resultados opostos" (p. 38). Tento, agora, ser mais convincente. Inicialmente, cabe lembrar que o aparentemente "óbvio" nem sempre é verdadeiro. A terra não é plana.

\footnotetext{
* Professor Sênior da Escola Superior de Agricultura "Luiz de Queiroz”, Universidade de São Paulo ESALQ-USP, Piracicaba-SP, Brasil. E-mail: hoffmannr@usp.br. Orcid: https://orcid.org/0000-0002-20778202. Submetido: 22/Fevereiro/21: Aprovado: 23/Fevereiro/2021.
} 
Também é importante ter em mente que o conceito estatístico de desigualdade obedece ao princípio do anonimato. José ganhar R \$ 1.000 e Gustavo ganhar R\$ 9.000 por mês é diferente de José ganhar R \$ 9.000 e Gustavo ganhar R \$ 1.000 por mês, mas, estatisticamente, trata-se de duas distribuições com a mesma desigualdade, com índice de Gini $(G)$ igual a 0,4.

Consideremos essa distribuição de renda muito artificial., com apenas duas pessoas: José com um salário de 1 (mil reais) e Gustavo com aposentadoria de 9. Como fica a distribuição se excluirmos a aposentadoria? Agora temos Gustavo com renda zero, José com renda 1 e $G=0,5$. A exclusão da aposentadoria fez o índice de Gini aumentar de 0,4 para 0,5. Na distribuição inicial o mais rico era Gustavo, que ficava com $90 \%$ de toda a renda e na nova situação o mais rico é José, que se apropria de $100 \%$ da renda total. Em uma situação simples como essa, é claro que, na situação inicial., se pudéssemos alterar arbitrariamente o valor da aposentadoria para diminuir a desigualdade, deveríamos reduzir seu valor para 1, jamais para zero. Não pode haver dúvida de que a desigualdade inicial., com $G=0,4$, está associada ao fato de a aposentadoria de Gustavo ser nove vezes maior do que o salário de José. Não faz sentido dizer, nessa situação, que a aposentadoria de Gustavo "contribui" para reduzir a desigualdade. A eliminação da aposentadoria de Gustavo não muda apenas o índice de Gini de 0,4 para 0,5; muda também a natureza da desigualdade; antes Gustavo era o rico; depois José é que fica em posição relativamente melhor.

Quando a inclusão ou não de uma parcela da renda não altera muito a ordenação das pessoas conforme valores crescentes da renda final., pode ser razoável avaliar o efeito dessa parcela na desigualdade por meio da simulação contrafactual na qual se exclui essa parcela. Mas para muitas pessoas as aposentadorias e pensões são seu único rendimento e elas ficam sem renda alguma na situação contrafactual. Parte dos que recebem aposentadorias ou pensões no Brasil estão entre os relativamente ricos e, na simulação, passam a ser miseráveis sem renda alguma. Como não há nenhum economista ou político maluco propondo extinguir todas as aposentadorias e pensões, essa simulação não tem nenhum significado prático. O que se discute, sim, são propostas de reduzir (ou aumentar) as aposentadorias e pensões. E existe procedimento estatístico apropriado para avaliar como mudanças marginais em uma parcela afetam a desigualdade da distribuição de renda.

Seja $x_{i}$ a renda da $i$-ésima pessoa, com as rendas ordenadas de maneira que $x_{i} \leq x_{i+1}$

Então $i$ indica a posição de ordem de cada pessoa, com as pessoas ordenadas da mais pobre à mais rica. Sendo $n$ o número de pessoas na população analisada e $\mu$ a renda média, o índice de Gini da distribuição da renda pode ser definido como uma função da covariância entre $i$ e $x_{i}$ :

$$
G=\frac{2}{n \mu} \operatorname{cov}\left(i, x_{i}\right)
$$

Se a renda $x_{i}$ é a soma de parcelas $x_{h i}, \operatorname{com} h=1,2, \ldots, k$, e $\mu_{h}$, e representa a média da $h$-ésima parcela, a razão de concentração dessa parcela é 


$$
C_{h}=\frac{2}{n \mu_{h}} \operatorname{cov}\left(i, x_{h i}\right)
$$

Note-se que no cálculo do índice de Gini entra a covariância entre $x_{i}$ e a própria posição de ordem. Essa covariância não pode ser negativa. Consequentemente, o índice de Gini também não pode ser negativo. Mas uma parcela pode ter covariância negativa com a posição de ordem das rendas finais e nesse caso a razão de concentração da parcela é negativa, como é o caso típico da renda do Bolsa-Família.

Seja $\varphi_{h}$ a participação da $h$-ésima parcela na renda total $\left(\varphi_{h}=\mu_{h} / \mu\right)$. Rao (1969) mostrou que o índice de Gini é uma média ponderada das razões de concentração das parcelas da renda:

$$
G=\sum_{h=1}^{k} \varphi_{h} C_{h}
$$

Considere-se um pequeno acréscimo proporcional em todos os valores da $h$-ésima parcela, de maneira que seus novos valores passem a ser $(1+\theta) x_{b i}$. Com $\theta=0,01$ teríamos um aumento de $1 \%$ no valor da parcela. Seja $\Delta G$ a consequente alteração no índice de Gini. Pode-se demonstrar ${ }^{1}$ que

$$
\lim _{\theta \rightarrow 0} \frac{\Delta G}{\theta}=\varphi_{h}\left(C_{h}-G\right)
$$

Trata-se do efeito marginal em $G$ causado por aumento proporcional em uma parcela. Para uma parcela positiva $\left(\varphi_{h}>0\right)$, o índice de Gini aumenta se a razão de concentração da parcela for maior do que o índice de Gini e diz-se, então, que a parcela é regressiva. Por outro lado, se $C_{h}<G$, o aumento porcentual na parcela causa redução no índice de Gini e diz-se que a parcela é progressiva. Cabe ressaltar, novamente, que para fins de orientação de política econômica, geralmente interessa o efeito de mudanças em uma parcela, e não o efeito de sa total eliminação. Ninguém está propondo a total eliminação de aposentadorias e pensões.

Cardoso, Dietrich e Souza (2021) analisam dados da PNAD de 1997 e 2007 e da PNAD Contínua de 2017. Em nenhum momento desenvolvem análise que permita captar o efeito de mudanças marginais nas aposentadorias e pensões e não mencionam análises sobre a evolução da contribuição de aposentadorias e pensões e de várias outras parcelas para a desigualdade da distribuição da renda domiciliar per capita (RDPC) usando dados da PNAD de 1995 a 2015 (Hoffmann, 2017) e dados anuais da PNAD Contínua de 2012 a 2019 (Hoffmann, 2020). Em Hoffmann (2017) verifica-se que de 1999 a 2015 a razão de concentração de aposentadorias e pensões pagas por órgãos do governo foi quase sempre um pouco maior do que o índice de Gini da distribuição da RDPC, revelando seu caráter regressivo. Os dados da PNAD Contínua mostram que o rendimento de aposentadorias e pensões reforça a elevada desigualdade da distribuição da RDPC no País. Em 2019, com índice de Gini igual a 0,543, a razão de concentração de aposentadorias e pensões

\footnotetext{
${ }^{1}$ Ver Hoffmann, Botassio e Jesus (2019), cap. 9.
} 
era igual a 0,549. Os dados da PNAD indicam uma clara tendência decrescente da desigualdade da distribuição da renda no Brasil de 2001 a 2015. Mas a tendência se inverte em 2015 e verifica-se que o rendimento de aposentadorias e pensões contribuiu para isso, com a correspondente parcela $\varphi_{h} C_{h}$ do índice de Gini crescendo substancialmente de 2015 a 2019 (Hoffmann, 2020)². Ao analisar o papel da previdência no aumento da desigualdade no Brasil a partir de 2015, Barbosa, Souza e Soares (2020, p. 36-37) afirmam que "Os benefícios previdenciários superiores a um salário mínimo foram os maiores culpados pela piora da distribuição de renda de 2017 a 2018 e um vilão secundário durante o período 2015-2018 como um todo".

É fundamental ter em mente que o caráter regressivo das aposentadorias e pensões decorre, em grande parte, da existência de regras distintas para os funcionários públicos e para os que recebem do INSS (Instituto Nacional do Seguro Social). Isso não pode ser visto nos dados da PNAD, onde não é possível separar esses dois tipos de aposentadorias e pensões. Mas na Pesquisa de Orçamentos Familiares (POF) 2008-2009 pode-se verificar que o índice de Gini da distribuição da renda familiar per capita é 0,561 , a razão de concentração de aposentadorias e pensões pagas pelo INSS é 0,480 e a referente a funcionários públicos é 0,822. Em 2017-2018 os valores são 0,535, 0,433 e 0,821, respectivamente (Hoffmann e Vaz, 2020). Aposentadorias e pensões pagas pelo INSS são progressivas, mas as referentes a funcionários públicos são fortemente regressivas.

Cardoso, Dietrich e Souza (2021) mostram, no Gráfico 7, a redução da desigualdade da distribuição de aposentadoria e pensões de 1997 a 2017 e sugerem que isso deve ter contribuído para aumentar a sua progressividade (ou reduzir a regressividade). Falta lógica nesse raciocínio. O gráfico mostra que a desigualdade foi avaliada considerando apenas seus valores positivos em cada ano e nem se menciona a variação da proporção de pessoas da população brasileira que recebia alguma aposentadoria ou pensão. A regressividade ou progressividade de uma parcela depende de sua covariância com a renda final., e não da desigualdade da distribuição dos valores positivos da parcela. Uma parcela concentrada nos ricos será fortemente regressiva mesmo que a desigualdade da distribuição dos valores (positivos) da parcela seja nula.

Finalmente, assinalo o uso errado do termo "quintil" no segundo parágrafo da p. 39. Quartil, quintil, decil e percentil são palavras criadas por Galton (1885) e se referem a separatrizes da distribuição. Assim como a mediana é a separatriz que divide a distribuição em duas partes iguais, os quatro quintis são valores da renda

\footnotetext{
${ }^{2}$ Cabe reconhecer que as análises realizadas em Hoffmann (2017) e Hoffmann (2020) levam em consideração apenas os benefícios recebidos, e não as contribuições pagas durante os anos de trabalho. A comparação de taxas internas de retorno para diversos tipos de aposentados, como a feita em Afonso e Fernandes (2005), pode mostrar algum tipo de redistribuição dentro do sistema de previdência, mas não permite concluir nada sobre a regressividade dos benefícios para toda a distribuição de renda no País. Além disso, Afonso e Fernandes não separam as aposentadorias e pensões do INSS e as de funcionários públicos.
} 
que dividem a distribuição em cinco quintos. As partes são os quintos. Quintis são definidos com rigor, por exemplo, em Davidson e MacKinnon (2004). O fato de a maioria dos economistas americanos usar o termo, em inglês, de maneira incorreta, não justifica fazer o mesmo em português.

\section{REFERÊNCIAS BIBLIOGRÁFICAS}

Afonso, I. E.; Fernandes, R. (2005) "Uma estimativa dos aspectos distributivos da previdência social no Brasil”. Revista Brasileira de Economia, v. 59(3): 295-334.

Barbosa, R. J.; Souza, P. H. G. F.; Soares, S. S. D. (2020) "Distribuição de renda nos anos 2010: uma década perdida para desigualdade e pobreza”. Brasília, IPEA, Texto para Discussão 2610.

Cardoso, E.; Dietrich, T. P. ; Souza, A. P. (2021) "Envelhecimento da população e desigualdade". Brazilian Journal of Political Economy, v. 41, n. 1, pp. 23-43, janeiro-março.

Davidson, R.; MacKinnon, J. G. (2004) Econometric theory and methods. Oxford University Press.

Galton, F. (1885) "Some results of the Anthropometric Laboratory". Journal of the Anthropological Institute, v. 14, p. 275-287.

Hoffmann, R. (2009) “Desigualdade da distribuição da renda no Brasil: a contribuição de aposentadorias e pensões e de outras parcelas do rendimento domiciliar per capita”. Economia e Sociedade, v. 18, n. 1(35), pp. 213-231.

Hoffmann, R. (2017) “Desigualdade da distribuição da renda no Brasil: o que mudou em 2015?” Texto para Discussão n. 38 do IEPE-Casa das Garças.

Hoffmann, R. (2020) "Parcelas regressivas e progressivas da renda domiciliar per capita e fatores associados à desigualdade da distribuição da renda no Brasil, 2012-2019”. Texto para Discussão $n$. 62 do IEPE-Casa das Garças.

Hoffmann, R.; Botassio, D. C.; Jesus, J. G. (2019) Distribuição de renda: medidas de desigualdade, pobreza, concentração, segregação e polarização. $2^{a}$ ed. São Paulo, EDUSP.

Hoffmann, R.; Vaz, D. V. (2020) "Mensurando a desigualdade no Brasil: evidências a partir da renda e dos gastos das famílias”. Texto para Discussão n. 63 do IEPE-Casa das Garças.

Rao, V. M. (1969) “Two decompositions of concentration ratio". Journal of the Royal Statistical Society: Series A (General), v. 132, n. 3, pp. 418-425. 


\title{
Envelhecimento da população e desigualdade - Resposta a Hoffmann
}

Population aging and inequality - Reply to Hoffmann

\author{
ELIANA CARDOSO* \\ THAIS PERES DIETRICH** \\ ANDRÉ PORTELA SOUZA****
}

RESUMO: Esta é uma resposta às críticas levantadas pelo Professor Rodolfo Hoffmann ao nosso artigo "Envelhecimento da população e desigualdade".

PALAVRAS-CHAVE: Distribuição de renda; desigualdade.

ABSTRACT: This is a reply to the criticisms raised by Professor Rodolfo Hoffmann to our article "Population aging and inequality".

KEYWORDS: Income distribution; inequality.

JEL Classification: D63.

Esta tréplica rebate as críticas de Rodolfo Hoffmann ao artigo "Envelhecimento da população e desigualdade". A maior preocupação de Hoffmann ("Aposentadorias e pensões no Brasil: progressivas ou regressivas?”) refere-se à possibilidade de que os experimentos em Cardoso, Dietrich e Souza (2021) possam estar comprometidos por comparar a distribuição de renda entre indivíduos que teriam uma renda nula antes da aposentadoria e uma renda alta depois da aposentadoria. Essa preocupação não procede, por causa da forma com foram construídas as situações em comparação.

Utilizamos o conceito de renda domiciliar familiar (renda de todas as fontes para maiores de 14 anos) e o número de pessoas no domicílio. Mesmo os indivíduos (sejam eles crianças, adultos desempregados ou idosos), que a nível individual não

\footnotetext{
* Escola de Economia de São Paulo, Fundação Getulio Vargas - EESP/FGV, São Paulo/SP, Brasil. E-mail: eliana.anastasia@gmail.com. Orcid: https://orcid.org/0000-0002-1670-7292.

* Centro de Microeconomia Aplicada, Fundação Getulio Vargas - C-Micro/FGV, São Paulo/SP, Brasil. E-mail: thaispdietrich@gmail.com.; Orcid: https://orcid.org/0000-0001-5095-0408.

*** Escola de Economia de São Paulo e Centro de Microeconomia Aplicada, Fundação Getulio Vargas EESP/FGV, São Paulo-SP, Brasil. E-mail: Andre.portela.souza@fgv.br. Orcid: https://orcid.org/000-00025988-2437. Submetido: 19/Março/2021; Aprovado: 19/Março/2021.
} 
têm rendimento, recebem uma parcela da renda do domicílio a que pertencem. Seria improvável, como no exemplo inventado por Hoffmann, que um indivíduo, que recebe uma pensão muito alta, venha de uma família muito pobre, tendo ganho durante toda sua vida uma renda quase nula e a seguir uma renda alta e generosa ao se aposentar.

Antes de prosseguir, vale a pena observar que a renda média dos idosos no Brasil, em 2017, se situava acima da renda média do resto da população. Mais importante ainda, antes mesmo de examinarmos a distribuição das aposentadorias e pensões, podemos comparar a distribuição da renda total entre as pessoas acima de 65 anos com a do resto da população na função de distribuição acumulada.

A função de distribuição acumulada, no Gráfico 5 de Cardoso, Dietrich e Souza (2021), mostra que, no caso da população com mais de 65 anos, seu rendimento (medido no eixo horizontal) é maior para todas as frequências (percentagem da população medida no eixo vertical) do que o rendimento da população com menos de 65 anos. A evidência confirma uma renda mais alta e mais bem distribuída entre as pessoas acima de 65 anos em relação ao resto da população.

Quando se lembra da importância das aposentadorias para a população acima de 65 anos, a evidência descrita no parágrafo anterior reforça a hipótese de que as aposentadorias reduzem a desigualdade. De fato, não é possível rejeitar essa hipótese quando examinamos as curvas de Lorenz para a renda domiciliar per capita com aposentadorias e a renda domiciliar per capita sem aposentadorias. Hoffmann argumenta que essa última comparação não faz sentido pois não tem "nenhum sentido prático" em suas próprias palavras. Ora, é precisamente isso que faz um sistema de previdência e assistência social., transferir renda para algumas pessoas que de outra maneira não teriam renda alguma.

Ainda assim, mesmo reduzindo a desigualdade, a previdência continua a perpetuar a profunda injustiça de nossa sociedade. A injustiça do nosso sistema previdenciário, que decorre em boa parte das regras que favorecem os funcionários públicos, é ilustrada pelos "subsídios previdenciários" calculados pelo Banco Mundial (2017). Os grupos mais pobres recebam uma parte menor desses subsídios, o grupo mais rico uma parcela maior. Apesar disso, os subsídios não são regressivos, porque grande parte deles cabe ao grupo do meio. Entretanto, os subsídios previdenciários para funcionários públicos merecem uma correção em futuras reformas, como argumentam Cardoso, Dietrich e Souza (2021).

Por último, agradecemos a Hoffmann sua preocupação com o português ao distinguir entre "quintos" e "quintis". E continuamos, ainda assim, a seguir a tradição acadêmica americana. 